\title{
Development and Validation of Method for Determination of Chloride in Surfactant Sample Using Auto-Titrator
}

\author{
Mahani Mamat", Salwani Abdullah, Sara Shahruddin, Noor Haida Sebran \\ Petronas Research Sdn. Bhd., Kajang, Malaysia \\ Email address: \\ mahanimamat@petronas.com.my (M. Mamat), salwani.abdullah@petronas.com.my (S. Abdullah), \\ sarashahruddin@petronas.com.my (S. Shahruddin), haida_sebran@petronas.com.my (N. H. Sebran) \\ ${ }^{*}$ Corresponding author
}

\section{To cite this article:}

Mahani Mamat, Salwani Abdullah, Sara Shahruddin, Noor Haida Sebran. Development and Validation of Method for Determination of Chloride in Surfactant Sample Using Auto-Titrator. Science Journal of Analytical Chemistry. Vol. 8, No. 2, 2020, pp. 78-85.

doi: $10.11648 /$ j.sjac.20200802.17

Received: May 18, 2020; Accepted: June 3, 2020; Published: June 17, 2020

\begin{abstract}
The chloride content for the newly developed surfactant is critical to ensure reaction completion and to minimize irritation issues that may be associated with having high chloride content. There are several methods used to determine the chloride content such as UV-visible and ion chromatography; however, both are known to have low accuracy and are less precise. Considering other factors such as skill, expertise, cost and time required, titration is the most suitable method for chloride determination because it is a simple, fast and relatively cheap method as compared to other methods. However, the precision achieved by manual titration is very much dependent on the operator's skill and ability to detect the color change accurately. To increase the precision and accuracy of the results generated, an auto-titrator that employs potentiometric sensors to determine the endpoint has been used to determine the chloride content. An improved method to determine the presence of chloride in surfactant solution is hereby illustrated, in which a commercial surfactant has been analyzed using the auto-titrator. A commercial surfactant known as Cola Teric CBS with a sodium chloride content of 5.7\% as stated in the Certificate of Assurance (COA) was analyzed using this method. Fifteen replicate titrations of the sample giving the average chloride content of 3.5\%. The precision for both method and system was found to be $0.28 \%$ and $2.22 \%$ respectively, which is within the acceptable limit. The good precision achieved by this method concludes the intention of the work to develop a method that ensures the endpoint can be determined accurately with better reproducibility, reduced titrant, sample and not operator dependent.
\end{abstract}

Keywords: Surfactant, Personal Care, Chloride Analysis, Autotitrator

\section{Introduction}

Surfactants are vital components in various personal care products and household products. The surfactant molecules are comprised of hydrophobic ("water-hating") and hydrophilic ("water-loving") moieties in their chemical structure which make them amphiphilic with the ability to form micelles in water $[2,3]$. The main characteristic of these compounds is to stabilize mixtures of oil and water by reducing the surface tension at the interface between the oil and water molecules. Thus, the surfactants will be able to provide various functions such as cleansing, wetting, foaming, emulsifying, conditioning and solubilizers [4].

The presence of other components in the product may affect the surfactant properties. One of the main components/salts contained in almost every personal care and household products is sodium chloride $(\mathrm{NaCl})$. The presence of $\mathrm{NaCl}$ in anionic and amphoteric surfactants enable them to achieve outstanding detergency, cleansing quality, good foaming property and easy thickening [5]. They are present as a byproduct of a two-step synthesis of amphoteric surfactants betaines whereby a tertiary amine, dimethylaminopropyl amine (DMAPA) is firstly reacted with a fatty acid or methyl ester followed by with a second reaction with sodium monochloroacetate as shown in the reaction schematic below (Figure 1) [6]. The typical salt content permissible is in the range of $6-8 \%$ [7]. The $\mathrm{NaCl}$ acts to enlarge the effective size of the surfactant micelles, which results in a viscosity increase. 


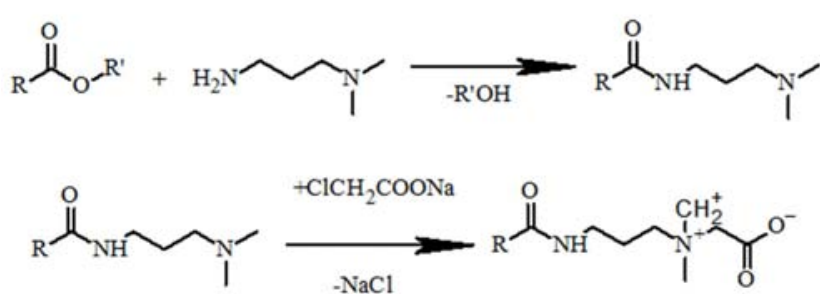

Figure 1. Synthesis pathway of amphoteric surfactant betaine.

$\mathrm{NaCl}$ is commonly used at thickener in hair care products; it cleanses and polishes the teeth as well as reduces oral odour [7, $8,9]$. However, $\mathrm{NaCl}$ has some disadvantages that it depresses the lathering effect of the soap, tends to form a scum ring around the bath and has no water-softening properties. Additionally, it contributes to the eye irritation experienced with hair care products, may cause dry and itchy scalp and may cause some hair loss [10]. Research has shown that the addition of $\mathrm{NaCl}$ in aqueous surfactant solution changes the solution properties and may affect the intramicellar and intermicellar interactions [11]. Because $\mathrm{NaCl}$ is added to the personal care products or its presence is resultant from the surfactant production, the amount present must be accurately determined so that it does not exceed the permissible limit.

The amount of $\mathrm{NaCl}$ present in the surfactant solution can be determined by measuring the chloride content in the solution. Titration has been the most widely used method to determine the chloride content in aqueous solution because it is straightforward to conduct, fast and relatively cheap as compared to other methods. However, the precision achieved by manual titration is very much dependent on the operator's skill and ability to detect the colour change accurately. Because of this, most laboratories prefer potentiometric titration to increase precision and accuracy of the results. Even though the presence of the potentiometric sensor for the determination of anionic species attracted less attention in a variety of chemical, clinical and environmental samples, we cannot argue that this sensor provided a direct, fast response and a cheaper way of performing ion measurements due to their small size, simple operation, portability and low energy consumption. These electrodes have proven useful for quantitative determination of anionic surfactants. The ion-selective sensors which are fast, convenient and require no sample treatment have provided an analytical procedure that overcomes the drawbacks of normal titration. It is also suitable for online analysis [12].

The chloride auto-titrator uses a potentiometric end-point to determine the amount of free (unbound) chloride in a solution. A silver nitrate reagent was aliquoted into unknown solution with the same amount of dissolved chloride in solution. As the silver nitrate is added, the following reaction occurs.

$$
\mathrm{Ag}^{+} \text {(aq) }+\mathrm{Cl}^{-} \text {(aq) } \mathrm{AgCl}(\mathrm{s})
$$

The product, $\mathrm{AgCl}$, is insoluble in water and forms precipitates. A silver-specific electrode in the solution measures a value proportional to the amount of free silver in the solution. As the silver chloride reagent is added, a measurement (in $\mathrm{mV}$ ) is taken from the silver-specific electrode. If the function of volume added versus the electrode reading is being considered and the volume where the second derivative of the function is 0 (or the inflection point), then the equivalence point has been determined (Figure 2).

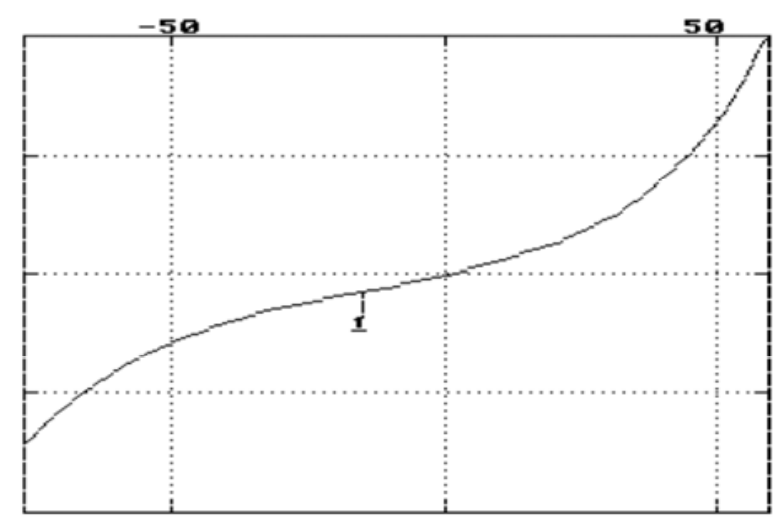

Figure 2. Potentiometric Equivalence Point.

For most purposes, this first equivalence point corresponds to the volume where all free chloride has been converted to $\mathrm{AgCl}$. Knowing the volume of reagent added, the concentration of reagent and the stoichiometric ratio between reagent and chloride (1: 1), we can determine the amount of chloride contained in the solution:

$$
\left.\left[\mathrm{Cl}^{-}\right]=([\mathrm{AgCl}]) \times \text { Volume }_{\left(\mathrm{AgNO}_{3}\right)}\right) / \text { Volume }_{(\text {Sample })}
$$

\section{Assumptions}

It is assumed that the first equivalence point corresponds to that of the $\mathrm{AgCl}$ reaction. Silver forms sparingly soluble precipitates with other anions as well as chloride. Solutions with high concentrations of bromide or iodide may cause an erroneous first equivalence point (as they titrate before chloride). In these cases, the method on the instrument will need to be adjusted to run past the first end-point and to determine the Volume (AgNO3) value. The reagent volumes for the non-chloride end-point must be subtracted from the reagent volume for the chloride end-point. It should be reasonably obvious which the chloride end-point is, and chloride will typically be many time more concentrated in situ than other anions [13].

In our laboratories, the manual titration which was developed and used for the determination of chloride in an aqueous sample is very much dependent on the operator's skill and ability to accurately detect the colour change (Table 1) [14]. To increase the precision and accuracy of the results generated, the auto-titrator method is used for the determination of chloride (Table 1). F-Test

Table 1. Determination of chloride using normal titration and auto titration.

\begin{tabular}{ll}
\hline Normal Titration & \\
\hline Sample & Chloride, $\mathbf{m g} / \mathbf{L}$ \\
\hline R1 & 36400 \\
R2 & 36900 \\
\hline
\end{tabular}




\begin{tabular}{ll}
\hline Normal Titration & \\
\hline Sample & Chloride, $\mathbf{~ m g / L}$ \\
\hline R3 & 37500 \\
R4 & 37400 \\
R5 & 36900 \\
R6 & 36200 \\
R7 & 36700 \\
R8 & 37300 \\
R9 & 36900 \\
R10 & 36600 \\
\hline
\end{tabular}

\begin{tabular}{ll}
\hline Auto Titration & \\
\hline Sample & Chloride, $\mathbf{m g} / \mathbf{L}$ \\
\hline 1 & 35100 \\
2 & 34900 \\
3 & 35000 \\
4 & 34900 \\
5 & 34900 \\
6 & 35000 \\
7 & 35000 \\
8 & 34800 \\
9 & 34900 \\
10 & 35100 \\
\hline
\end{tabular}

To compare the differences between these two (2) methods, the F-test is performed to prove that the two (2) methods are not equal (Table 2).

Table 2. F-test two-sample for variances.

\begin{tabular}{lll}
\hline & Variable 1 & Variable 2 \\
\hline Mean & 36880 & 34960 \\
Variance & 181777.7778 & 9333.333333 \\
Observations & 10 & 10 \\
df & 9 & 9 \\
$\mathrm{~F}$ & 19.47619048 & \\
$\mathrm{P}(\mathrm{F}<=\mathrm{f})$ one-tail & $7.21984 \mathrm{E}-05$ & \\
$\mathrm{~F} \mathrm{Critical} \mathrm{one-tail}$ & 3.178893104 & \\
\hline
\end{tabular}

$\mathrm{F}(19.47)>\mathrm{F}$ critical (3.17) Therefore, the variance between the normal titration and auto titration is significant. These two tests are not equal; therefore, the method validation is conducted.

\section{Materials and Methods}

The surfactant sample identified as Cola Teric CBS was purchased from one of the surfactant manufacturers and was used in this study. According to the manufacturer's information, the surfactant consists of $5.7 \%$ chloride content.

For sample preparation, $0.1 \mathrm{~g}$ of the sample was accurately measured and transferred into a clean and dry beaker. The sample was dissolved and marked up to a final volume of 80 $\mathrm{mL}$ with deionized water. The solution was shaken vigorously to ensure the homogenization of the sample.

The element for the validation of the methods is based on Eurachem Guideline. The performance characteristics were selected based on the relevant validation parameters for the in house developed method, which is listed below;

1. Selectivity

2. Linearity and Operation Range

3. Accuracy \& Recovery

4. Method Detection Level

\section{Method Precision (Repeatability) \\ 6. Robustness \\ 7. Measurement of Uncertainty}

\subsection{Selectivity}

The parameter was supposed to be measured by spiking the surfactant with other elements in the same group with chlorides such as fluoride, bromide or iodide. However, this parameter was not able to be performed due to the unavailability of the other elements in higher concentration. This is because the expected concentration of chloride in the surfactant is 5.7 wt. $\%$.

\subsection{Linearity and Operation Range}

The parameter is not applicable for this method since there is no calibration involve for the autosampler

\subsection{Accuracy and Recovery}

Accuracy is the ability to give responses close to a true value. Recovery is the fraction of analyte added in the test sample matrix, and its response is measured. For this study, the sample solutions were spiked with $25000 \mathrm{mg} / \mathrm{L}$ of chloride.

The percentage recovery is calculated using the following equation:

Percentage recovery $=\frac{\text { chloride value determined } \times 100}{\text { true value of chloride in sample }}$

\subsection{Method Detection Level}

Detection limits are estimates of concentration at which can be reasonably certain that the compound is present and the concentration below this limit may not be detected. This is important in trace analysis; however, for higher concentration, the value is not very critical. The formula used for the method detection limit is $3 \mathrm{x}$ Standard Deviation (SD).

\subsection{Method Precision (Repeatability)}

Precision is the measure of the degree of repeatability of an analytical method under regular operation. It is usually expressed as the standard deviation (SD) or the percent relative standard deviation (\%RSD) for a statistically significant number of samples.

In this method development, the precision of method and system were measured by preparing 10 replicates of samples, and 10 replicates each of $4 \mathrm{mg} / \mathrm{L}$ standard solution of chloride respectively. The percentage of Relative Standard Deviation (RSD) for both method and system were calculated. From the observation, the $\%$ RSD was found to be within the specification (\% RSD should not be more than 10\%) and were acceptable.

\subsection{Measurement of Uncertainty}

Measurement of uncertainty [15] is a parameter associated with the result of a measurement, characteristics 
of the dispersion of the values that could reasonably be attributed to the measurand. Measurement of uncertainty estimate takes into account all of the recognized effects operating on the result. The uncertainties associated with each effect are combined according to well-established procedures. Table 3 listed reagent and chemical used in this validation method.
Table 3. Reagents used for the analysis.

\begin{tabular}{ll}
\hline Chemical/Reagent & Grade \\
\hline Sodium chloride & Analytical Grade \\
Silver Nitrate & Analytical Grade \\
Chloride Standard, $1000 \mathrm{mg} / \mathrm{L}$ & Analytical Grade \\
Deionized Water & Type 1 \\
\hline
\end{tabular}

The process of the determination is as in Figure 3.

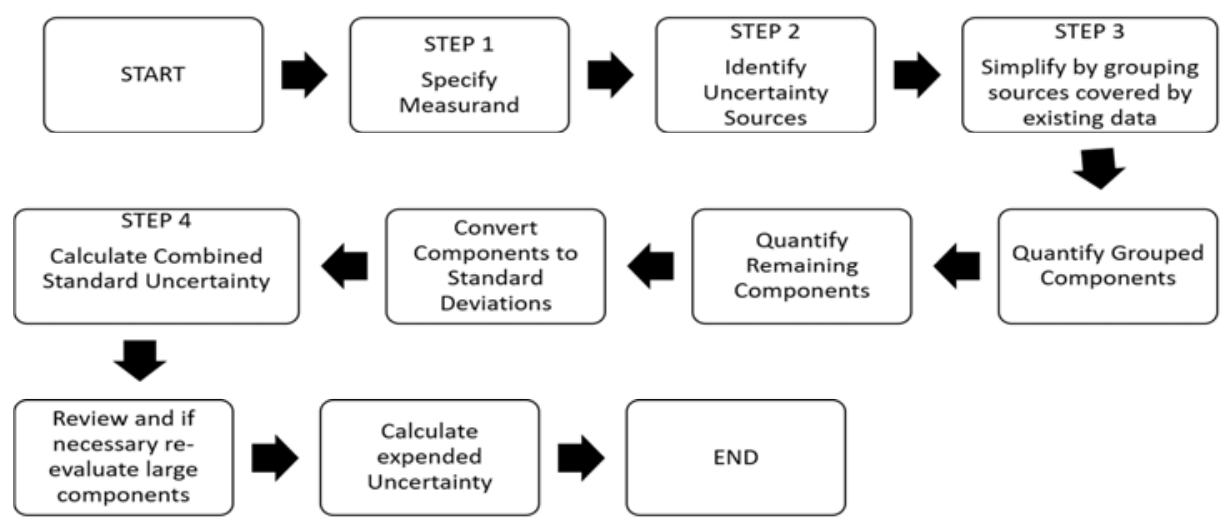

Figure 3. The uncertainty determination process.

\section{Results and Discussion}

Table 4 shows the recovery of chloride content for ten (10) duplicate samples which has been spiked with $25,000 \mathrm{mg} / \mathrm{L}$ chloride. The percentage range of recovery for chloride content was $97.8 \%$ to $99.8 \%$. This is within the acceptance criteria of $\pm 30 \%$. It confirms the accuracy of the method.

Table 4. Percent recovery of chloride content in surfactant.

\begin{tabular}{llllll}
\hline Sample & $\begin{array}{l}\text { Actual } \\
\text { Reading }\end{array}$ & $\begin{array}{l}\text { Actual reading } \\
\text { / ratio (1: 5) }\end{array}$ & $\begin{array}{l}\text { Spiked } \\
\text { Reading }\end{array}$ & $\begin{array}{l}\text { Spiked } \\
\text { Recovery }\end{array}$ & $\begin{array}{l}\text { \% } \\
\text { Recovery }\end{array}$ \\
\hline S1 & 35100 & 7020 & 31700 & 24700 & 98.7 \\
S2 & 34900 & 6990 & 31400 & 24500 & 97.8 \\
S3 & 35000 & 6990 & 31900 & 24900 & 99.6 \\
S4 & 34900 & 6990 & 31800 & 24800 & 99.4 \\
S5 & 34900 & 6990 & 31900 & 24900 & 99.7 \\
S6 & 35000 & 7000 & 31900 & 24900 & 99.6 \\
S7 & 35000 & 7000 & 31900 & 24900 & 99.5 \\
S8 & 34800 & 6970 & 31900 & 24900 & 99.7 \\
S9 & 34900 & 6980 & 31900 & 24900 & 99.8 \\
S10 & 35100 & 7010 & 32000 & 24900 & 99.8 \\
\hline
\end{tabular}

Table 5 showed the data collected on the spiked standard of $4 \mathrm{mg} / \mathrm{L}$; the detection limit for the method was found to be 0.3 $\mathrm{mg} / \mathrm{L}$ of chloride.

Table 5. Chloride content for fifteen replicates of $4 \mathrm{mg} / \mathrm{L}$ spiked standard.

\begin{tabular}{ll}
\hline Sample & Sample reading $(\mathbf{m g} / \mathbf{L})$ \\
\hline 1 & 4.35 \\
2 & 4.35 \\
3 & 4.44 \\
4 & 4.20 \\
5 & 4.25 \\
6 & 4.29 \\
7 & 4.32 \\
8 & 4.10 \\
\hline
\end{tabular}

\begin{tabular}{ll}
\hline Sample & Sample reading $(\mathbf{m g} / \mathbf{L})$ \\
\hline 9 & 4.35 \\
10 & 4.34 \\
11 & 4.19 \\
12 & 4.20 \\
13 & 4.30 \\
14 & 4.16 \\
15 & 4.15 \\
STD & 0.095827 \\
$3 \times$ STD & 0.287481 \\
Method Detection Limit & 0.3 \\
\hline
\end{tabular}

Table 6 and Table 7 showed the Precision results for the method and for the system. The $\%$ RSD for method and system was found to be $0.28 \%$ and $2.22 \%$ respectively. The $\%$ RSD should not exceed more than 10\%, hence the Precision for method and system where both are within the acceptable range.

Table 6. Precision result for the method.

\begin{tabular}{ll}
\hline Sample & mg/L Chloride \\
\hline 1 & 35100 \\
2 & 34900 \\
3 & 35000 \\
4 & 34900 \\
5 & 34900 \\
6 & 35000 \\
7 & 35000 \\
8 & 34800 \\
9 & 34900 \\
10 & 35100 \\
Mean & 34960 \\
Standard Deviation & 96.60917831 \\
$\%$ RSD & 0.28 \\
\hline
\end{tabular}


Table 7. Precision result for system.

\begin{tabular}{ll}
\hline Sample & $\mathbf{m g} / \mathbf{L}$ Chloride \\
\hline 1 & 4.35 \\
2 & 4.35 \\
3 & 4.44 \\
4 & 4.20 \\
5 & 4.25 \\
6 & 4.29 \\
7 & 4.32 \\
8 & 4.10 \\
9 & 4.35 \\
10 & 4.34 \\
Mean & 4.30 \\
Standard Deviation & 0.095272 \\
$\%$ RSD & 2.22 \\
\hline
\end{tabular}

Measurement of Uncertainty for this method was calculated by using the guide in Figure 2 above, and the Expanded Uncertainty for the method is 0.01 at a $95 \%$ Confidence Level. The flow and table shared below are the way how the Measurement of Uncertainty was obtained.
Step 1: Specify

Methodology:

a) Weigh approximately $0.1 \mathrm{~g}$ of sample into a $100 \mathrm{~mL}$ beaker. Dissolve and mark up to $80 \mathrm{~mL}$ with DI water

b) Analyze by auto-titrator

c) The concentration of chloride in the unknown sample is determined based on the end-point of the titration where the instrument reading at which the greatest change in voltage has occurred for a small and constant increment of silver nitrate added.

Calculation:

$\mathrm{mg} \mathrm{Cl} / \mathrm{L}=(\mathrm{A}-\mathrm{B}) \times \mathrm{N} \times 35450 /$ volume of sample

Where $\mathrm{A}=\mathrm{mL}$ of $\mathrm{AgNO} 3$

$\mathrm{B}=\mathrm{mL}$ of blank

$\mathrm{N}=$ concentration of titrant

Step 2: Identify Cause and Effect

Uncertainties contribute by a combination of factors for the method (Figure 4).

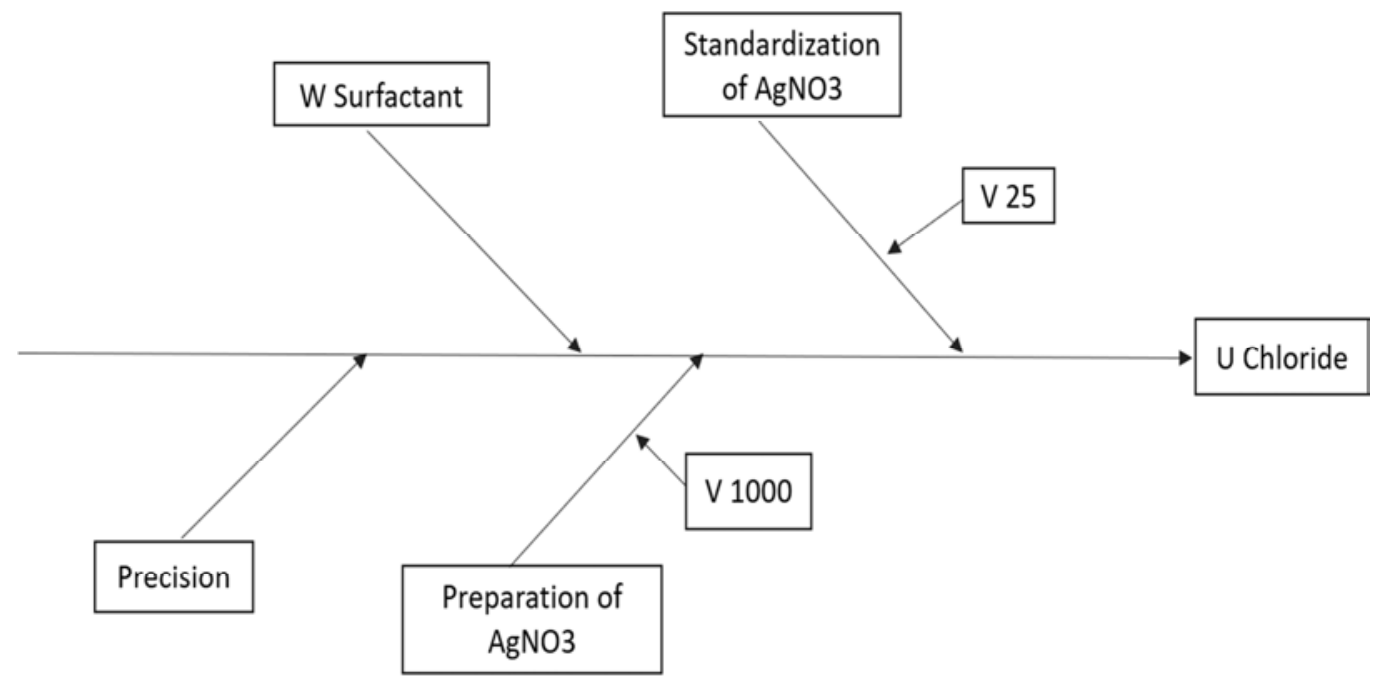

Figure 4. Cause and effect fishbone diagram.

Step 3: Quantify

a) Precision, range of sample matrices, range of analyte concentration (Table 8)

Table 8. Precision for the method.

\begin{tabular}{ll}
\hline Sample & mg/L Chloride \\
\hline 1 & 35100 \\
2 & 34900 \\
3 & 35000 \\
4 & 34900 \\
5 & 34900 \\
6 & 35000 \\
7 & 35000 \\
8 & 34800 \\
9 & 34900 \\
10 & 35100 \\
Mean & 34960 \\
Standard Deviation & 96.60917831 \\
RSD & 0.00276342 \\
\hline
\end{tabular}

b) Recovery

Method Recovery, Rm (Analysis of chloride standard spiked into sample matrices)

Method of sample preparation:

1. The sample solutions were spiked with $25000 \mathrm{mg} / \mathrm{L}$ of chloride.

2. Weigh approximately $50 \mathrm{~g}$ of sodium chloride solid, dilute in $1.0 \mathrm{~L}$ of DI water, to make $30000 \mathrm{mg} / \mathrm{L}$ stock solution.

3. Measure the exact volume to prepare spike sample with a concentration of $25000 \mathrm{mg} / \mathrm{L}$ chloride.

4. From the calculation, pipette $83.3 \mathrm{~mL}$ of $30,000 \mathrm{mg} / \mathrm{L}$ sodium chloride and markup until $100 \mathrm{~mL}$ with the sample.

5. Analyze the sample for chloride content (Figure 5 and Figure 6). 


\begin{tabular}{|c|c|c|c|c|c|}
\hline & Value, $x$ & Specification & Distribution / k & $\mu s$ & $\mu \mathrm{s} / \mathrm{x}$ \\
\hline \multicolumn{6}{|l|}{ a) Uncertainty of $100 \mathrm{ml}$ Volumetric flask } \\
\hline $100 \mathrm{ml}$ Volumetric flask, $100 \mathrm{mg} / \mathrm{L}$ Chloride & 100 & & & & \\
\hline Specification & & 0.1 & 1.732 & 0.057736721 & \\
\hline Temp variation & 3 & 0.00021 & 1.732 & 0.000121247 & \\
\hline Combined Uncertainty for $100 \mathrm{ml}$ flask & & & & 0.057736848 & 0.00058 \\
\hline \multicolumn{6}{|l|}{$\begin{array}{l}\text { b) Uncertainty of volume } 1000 \mathrm{ml} \\
\text { (Volumetric flask) }\end{array}$} \\
\hline $1000 \mathrm{ml}$ volumetric flask & 1000 & 0.4 & 1.73205 & 0.23094 & \\
\hline Temp variation & 3 & 0.00021 & 1.73205 & 0.00036 & \\
\hline $\begin{array}{l}\text { Combined Uncertainty for } 1000 \mathrm{ml} \\
\text { volumetric flask }\end{array}$ & & & & 0.23094 & 0.00023 \\
\hline \multicolumn{6}{|l|}{ e) Uncertainty of mass 0.1 gram } \\
\hline Tare & 0 & 0.0002 & 1.73205 & 0.00035 & \\
\hline Mass of sample, $0.1 \mathrm{~g}$ & 0.1 & 0.0002 & 1.73205 & 0.00001 & \\
\hline Comb uncertainty for $0.1 \mathrm{~g}$ sample, $\mu_{\mathrm{m}}$ & & & & 0.00035 & 0.00347 \\
\hline Combined Uncertainty of spike solution & & & & & 0.00351 \\
\hline
\end{tabular}

Figure 5. Uncertainty of glassware.

\begin{tabular}{|c|c|}
\hline Recovery & Value $\mathrm{x}, \mathrm{mg} / \mathrm{L}$ \\
\hline Cspike & 25000 \\
\hline Uspike & 0.00351 \\
\hline Determination & Cobs \\
\hline 1 & 24700 \\
\hline 2 & 24500 \\
\hline 3 & 24900 \\
\hline 4 & 24800 \\
\hline 5 & 24900 \\
\hline 6 & 24900 \\
\hline 7 & 24900 \\
\hline 8 & 24900 \\
\hline 9 & 24900 \\
\hline 10 & 24900 \\
\hline $\mathbf{n}$ & 10 \\
\hline mean Cobs & 24830.00 \\
\hline sample sd & 133.74935 \\
\hline rsd & 0.00539 \\
\hline U of Cobs (sd of mean) & 42.29526 \\
\hline mean $\mathbf{R}=$ Cobs/Cspike & 0.99320 \\
\hline URm =RxSQRT((UCobs/Cobs)2 + (Uspike/Cspike)2) & 0.00169 \\
\hline significance test, (1-Rm)/Urm & \\
\hline tcrit for (n-1) dof (9 degree of freedom) & 1.833 \\
\hline tcalc $=(1-\mathrm{Rm}) / \mathrm{URm}-$ absolute value & 4.019363058 \\
\hline t-test & \\
\hline $\begin{array}{l}\text { If tcalc }<\text { tcrit, the recovery is not significantly different from } 1- \\
\text { so results are not corrected for recovery. URm }=(\text { tcrit } x \\
\text { URm) } / 1.96\end{array}$ & 0.001582188 \\
\hline If tcalc>tcrit, corrected URm" = sqrt[(1-Rm)/k]^2 + URm^^2] & 0.003859906 \\
\hline
\end{tabular}

Figure 6. Recovery study.

c) The uncertainty associated with the standardization of silver nitrate (Figure 7).

Method of preparation:

1. Measure $25 \mathrm{~mL} 0.0141 \mathrm{~N}$ sodium chloride solution into $150 \mathrm{~mL}$ beaker.

2. The solution was then titrated against silver nitrate. 


\begin{tabular}{|c|c|c|c|c|c|}
\hline Uncertainty of Silver Nitrate solution, UAgNO3 & Value, $x$ & Specification & Distribution/k & $\mu s$ & $\mu \mathrm{s} / \mathrm{x}$ \\
\hline \multicolumn{6}{|l|}{ b) Uncertainty of volume $1000 \mathrm{ml}$ (Volumetric flask) } \\
\hline $1000 \mathrm{ml}$ volumetric flask & 1000 & 0.4 & 1.73205 & 0.23094 & \\
\hline Temp variation & & 0.00021 & 1.73205 & 0.00036 & \\
\hline comb uncertainty for $1000 \mathrm{ml}$ volumetric flask & & & & 0.23094 & 0.00023 \\
\hline \multicolumn{6}{|l|}{ b) Uncertainty of volume $25 \mathrm{ml}$ (pipette) } \\
\hline $25 \mathrm{ml}$ pipette & 25 & 0.3 & 1.73205 & 0.51962 & \\
\hline Temp variation & 3 & 0.00021 & 1.73205 & 0.00036 & \\
\hline comb uncertainty for $25 \mathrm{ml}$ & & & & 0.51962 & 0.02078 \\
\hline \multicolumn{6}{|l|}{ d) Repeatability of standardisation } \\
\hline Determination & Value, $\mathrm{N}$ & & & & \\
\hline 1 & 0.0142 & & & & \\
\hline 2 & 0.0142 & & & & \\
\hline 3 & 0.014 & & & & \\
\hline 4 & 0.014 & & & & \\
\hline 1 & 0.0143 & & & & \\
\hline 2 & 0.0142 & & & & \\
\hline 3 & 0.0142 & & & & \\
\hline 4 & 0.014 & & & & \\
\hline 5 & 0.014 & & & & \\
\hline 6 & 0.014 & & & & \\
\hline n & 6 & & & & \\
\hline mean & 0.01412 & & & & \\
\hline Std & 0.00012 & & & & \\
\hline RSD & 0.00848 & & & & \\
\hline & & & & & \\
\hline Combined Uncertainy of Silver Nitrate Solution & & & & & \\
\hline $\left.\mathrm{U}=\mathrm{C}^{*} \mathrm{SQRT}\left(\mathrm{U}_{\mathrm{V} 1000} / 1000\right)^{\wedge} 2+\left(\mathrm{UV}_{25} / 25\right)^{\wedge} 2+\mathrm{Urep}^{\wedge} 2\right)$ & 0.00224 & & & & \\
\hline
\end{tabular}

Figure 7. Uncertainty contributed by standardization of silver nitrate.

Step 4: Combination

Figure 8 below shows the combination of uncertainty components contributed by various factors of the method.

\begin{tabular}{|c|c|c|c|c|c|}
\hline Uncertainty components & & Specification & Distribution/k & $\mu \mathrm{s}$ & $\mu \mathrm{s} / \mathrm{x}$ \\
\hline & Value, $x$ & & & & \\
\hline i) Precision & & & & & 0.00276 \\
\hline i) Recovery, UR, based on corrected Urm & & & & & 0.00386 \\
\hline \multicolumn{6}{|l|}{ iii) Measured weight 0.1 gram of sample } \\
\hline Tare & 0.00 & 0.0002 & 2.449489743 & $8.16497 \mathrm{E}-05$ & \\
\hline Mass of sample & 1 & 0.0002 & 1.732050808 & 0.00011547 & \\
\hline comb uncertainty for $1 \mathrm{gram}$ of sample & & & & 0.000141421 & 0.00014 \\
\hline iv) Standardisation of $\mathrm{AgNO} 3$ & & & & & 0.00224 \\
\hline \multicolumn{6}{|c|}{ 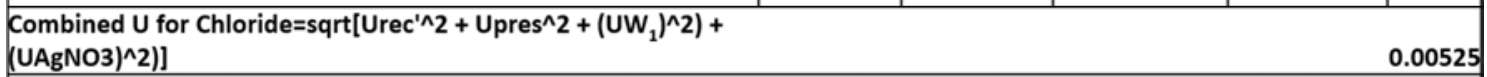 } \\
\hline Expanded U, k=2 (at 95\% confidence level) & & & & & 0.01050 \\
\hline
\end{tabular}

Figure 8. Combination of uncertainty for the method.

\section{Conclusions}

The proposed method of auto-titration for chloride determination in surfactant was found to be precise and accurate. The ruggedness of the method could not be determined due to the unavailability of other halide standards with high concentration. The concentration of halide standard required should be in the range of at least $10 \%$ concentration. The values of percentage recovery and standard deviation showed the sensitivity of the method. The method was validated entirely since the results showed satisfactory data for all the parameters of validation. Hence the method is recommended for analysis of total chloride in surfactant samples.

\section{References}

[1] Instruments, H. Top 5 reasons Why You Should Move to Automated Titration.

[2] Popadyuk, A., Samanta, S., Alam, S., Kalita, H., Chisholm, B. J., and A. Voronov (2016) Soy-based Polymeric Surfactants for Personal Care Applications: A Review. Surfactants Hair Care.

[3] Tadros, T. F. (2005) Applied Surfactants: Principles and Applications. Wiley-VCH Verlag GmbH \& Co. KGaA. 
[4] Staszak, K., Wieczorek, D. and K. Michocka (2015) Effect of Sodium Chloride on the Surface and Wetting Properties of Aqueous Solutions of Cocamidopropyl betaine. J. Surfactants Deterg. 18: 321-328.

[5] Madunic-Cacic, D., Sak-Bosnar, M., Matesic-Puac, R., and M. Samardzic (2012) Potentiometric Determination of Anionic Surfactants in Formulations Containing Cocoamidopropyl Betaine. Int. J. Electrochem. Sci. 7 (1): 875-885.

[6] S. Herrwerth, H. Leidreiter, H. H. Wenk, M. Farwick, I. Ulrich-Brehm and B. Gruning (2008) Highly Concentrated Cocamidopropyl Betaine - The Latest Developments for Improved Sustainability and Enhanced Skin Care. Tenside Surfactants Deterg. 45 (6): 304-308.

[7] Klein K, and I. Palefsky (2007) Shampoo Formulation. Handb Cleaning/Decontamination Surfaces. 1: 277-304.

[8] Cornwell, P. A. (2018) A review of Shampoo Surfactant Technology: Consumer Benefits, Raw Materials and Recent Developments. Int. J. Cosmet. Sci. 40 (1): 16-30.

[9] Sakamoto, K., Lochhead, R., Maibach, H. and Y. Yamashita
(2017) Cosmetic Science and Technology: Theoretical Principles and Applications. 1st ed. Sakamoto, K., editor. Elsevier.

[10] Poucher's Perfumes, Cosmetics and Soaps. $10^{\text {th }}$ Edition. Kluwer Academic Publishers.

[11] Car, T. R., Pham, Q. T. and D. Blankschtein (1994) Salt Effects on Intramicellar Interactions and Micellization of Nonionic Surfactants in Aqueous Solutions. Langmuir. 10 (1): 109-121

[12] Gupta, V. K., Goyal, R. N. and R. A. Sharma (2009) Chloride Selective Potentiometric Sensor based on a Newly Synthesised Hydrogen Bonding Anion Receptor. Electrochimica Acta. 54: 4216-4222.

[13] Bennight, C. (2011) Chloride by Autotitrator: Quick Start Guide", International Ocean Discovery Program.

[14] Standard Methods For the Examination of Water and Wastewater (2012) $22^{\text {nd }}$ Edition. - Method 4500-Cl-B-Argentometric Method, pp 4-72 - 4-73.

[15] Eurachem/CITAC Guide CG4 Quantifying Uncertainty in Analytical Measurement. - $2^{\text {nd }}$ Edition (2000). 